\title{
Preference Variation in Volunteering Decisions: Public Goods and Private Benefits
}

\author{
Bert Weemaes ${ }^{\text {a, }}{ }^{,}$, Erik Schokkaert ${ }^{\mathrm{b}}$ \\ ${ }^{\mathrm{a}}$ Department of Marketing and Organization, K.U.Leuven. Naamsestraat 69, 3000 Leuven, \\ Belgium. \\ b Department of Economics, K.U.Leuven. Naamsestraat 69, 3000 Leuven, Belgium and \\ CORE, Université catholique de Louvain. Voie du Roman Pays 34, 1348 Louvain-la-Neuve, \\ Belgium.
}

\begin{abstract}
We use data from the Survey of Health, Ageing and Retirement in Europe (SHARE) to explain the amount of time invested in volunteering in eight European countries. Direct information on motivations adds to the explanation over and above the effect of sociodemographic variables. The results for specific motivations are in line with the predictions from rational choice theory. While larger levels of 'warm glow' and 'instrumental' motivations lead to more frequent volunteering, the influence of the 'public good' motivation on volunteering frequency is found to be negligible.
\end{abstract}

JEL classification: J22, L31

PsycINFO classification: 2910,3020

Keywords: Volunteering, Motivations, Warm glow, Public good.

\footnotetext{
${ }^{*}$ Corresponding author. Tel.: +32 163269 40. Fax: +32 16326732.

E-mail address:bert.weemaes@econ.kuleuven.be.
} 


\section{Introduction}

Volunteering is an important activity in modern economies. According to the Bureau of Labor Statistics, approximately 61.8 million Americans, or $26.4 \%$ of the U.S. population, volunteered at least once through or for an organization between September 2007 and September 2008. For Europe, a Eurobarometer (2007) survey revealed that in $200634 \%$ of the population aged 15 and over, living in the 25 EU-Member States, claimed to participate actively or to do voluntary work in a non-profit organization. How can we explain that such a large fraction of the population is apparently willing to work without receiving a financial remuneration?

Psychologists have always been interested in the motivations behind volunteering and helping behaviour and have suggested and tested a wide range of alternative hypotheses. Economists are traditionally more reluctant to introduce motivations (or, in their jargon, preference variation) in their explanatory models. However, the analysis of volunteering (and donating) behaviour is an exception to this tradition (see also Prouteau and Wolff, 2008; Schokkaert, 2006). In fact, the importance of volunteering activities raises a puzzle for the rational choice paradigm. The most natural hypothesis for explaining volunteering is to interpret it as a voluntary contribution of time for the production of a 'public good'. Yet, if individuals are in the first place motivated by such a concern for the public good, rational free-rider theory predicts that in large populations contributions should be minimal, a hypothesis which does not fit the empirical reality. To avoid this free-rider prediction, alternative motivations have been put forward, all implying that volunteering does not only yield public but also private benefits to the volunteers. These private benefits can be either of an instrumental nature or related to psychological feelings of 'warm glow' (Andreoni, 1989, 1990). While the source of these warm glow feelings is not always unambiguously defined, its most common 
interpretations (related to a sense of duty, or to the desire of being socially rewarded by obeying generally accepted norms) are strikingly related to the motives that also appear in the psychological literature. Disentangling the structure of motivations behind volunteering behaviour is interesting from a theoretical point of view as it is one of the domains where findings from the psychological and the economic literature can be mutually enriching, and were both the potential and the limitations of the rational choice paradigm come strongly to the fore.

A better understanding of the motivations underlying volunteering behaviour is also important from a social policy point of view. First, the underlying reasons for volunteering determine how individuals adjust their contribution in reaction to an increase of the time donated by others, or in reaction to improved government provision. If giving is motivated by concern for a public good, contributions by others and by the government may crowd-out the own contributions of free-riding donors, as they are considered to be perfect substitutes for each other. However, there should be no similar crowding-out effect if people donate their time for their private benefit, as this benefit derives only from the amount of their own contribution (Andreoni, 1990; Harbaugh et al., 2007; Menchik and Weisbrod, 1987; Schiff, 1990). In this case volunteering may even be stimulated by government contributions, as these may spread information or act as a signal that the cause is socially valuable - and hence that contributing is also a duty for the citizens.

Second, the best way to attract and to retain volunteers in a non-profit organization is to fulfil their expectations (Brudney, 1990; Clary et al., 1992). Therefore, understanding why individuals are interested in volunteering enables volunteer coordinators to optimize their recruitment efforts by organizing them around the needs of their target group. Moreover, 
insights concerning volunteers' motivations are also important in explaining why individuals choose to volunteer rather than to donate money, which again is useful information for charitable organizations.

In this paper we use direct survey information to see which motives are most important to explain peoples' volunteering decisions. While the literature suggests several possible motives for volunteering, little is known about how they simultaneously operate and about the impact of the different motives (or combinations of motives) on the amount of time spent in volunteering. More specifically, we focus on the dichotomy between concern for the public good on the one hand and private benefits on the other hand. We analyse whether this distinction is empirically meaningful and whether the free-riding hypothesis is useful to understand reality.

This paper is structured as follows. Section 2 distinguishes more explicitly the different motives for volunteering and formulates our hypotheses. Section 3 describes the data and contains a first exploratory analysis of the hypotheses. The results of a more elaborate statistical model are presented in section 4. Section 5 discusses the implications of our results. Section 6 concludes.

\section{Motives for volunteering}

Different explanations of volunteering have been proposed in the literature. Traditionally the focus is on how socio-economic variables influence the amount of volunteering time. These variables typically serve as proxies for personal living situation and/or human, social and cultural capital (see Smith, 1994; Wilson, 2000 for comprehensive reviews). Economists 
would interpret this approach as reflecting the assumption of 'constant and identical preferences'. Apart from this research into the socio-economic drivers of volunteering behaviour, a number of authors have also studied the influence of motivations. Generally, three groups of explanations can be distinguished.

The first explanation states that volunteers are driven by the desire to increase the level of provision of some 'public good' (Duncan, 1999; Schiff, 1990). This motivation has been called 'pure altruism' (Andreoni, 1990). It implies that the value an individual attributes to her own contributions is equal to the value she attributes to the contributions of others and that it does not make a difference whether she herself or someone else is responsible for the contributions that bring the public good to the desired level. Rational choice theory predicts that with this motivation 'free-rider' problems are to be expected (Marwell, 1982; Samuelson, 1954). In large groups all individuals receive the collective good, but no single member's efforts can significantly affect its production. All individuals may want the public good to be available, yet they would rather let someone else make the necessary contributions (Weisbrod, 1975). Moreover, tax-funded government expenditures to provide a public good will reduce private giving, potentially dollar for dollar, as people cut their voluntary contributions in response to the higher taxes (Bergstrom et al., 1986). Applied to volunteering, these theoretical models imply that individuals may be strongly 'motivated' (or claim to be strongly motivated) by concern for the public good, yet volunteer little. We predict that when people hold a public good motivation, the strength of this motivation will have only a limited effect on actual volunteering. 
A second view holds that the volunteer is driven by feelings of "warm glow' following from his 'good deeds' (Andreoni, 1990), by pride (Piliavin and Charng, 1990) or by prestige and reputation gains (Schiff, 1990). A volunteer that is solely motivated by warm glow does not care about the absolute level of provision of the public good, but only seeks the private psychological benefits that ensue directly from his or her own donation of time or money.

Thirdly, volunteering can be used as an 'instrument' or as an investment to indirectly obtain other beneficial private outcomes. One resultant benefit of volunteering is that it leads to the acquisition of useful skills and experience and thus serves as an investment in human capital (Day and Devlin, 1998; Menchik and Weisbrod, 1987; Schram and Dunsing, 1981). Likewise, volunteering can be used as a way to build, maintain and strengthen friendly relationships (Glaeser et al., 2002; Prouteau and Wolff, 2008). Moreover, simply enjoying the work may also drive volunteers (Davis-Smith, 1998; Lynn and Davis-Smith, 1991). An important difference with the warm glow view explained above, is that if volunteers are driven only by 'instrumental motivations', volunteering will be equally meaningful to them even if they would know they are unproductive in terms of producing a public good. Note that these instrumental benefits can, for the most part, only be achieved by volunteering, contrary to the public good and warm glow benefits which can also be acquired by donating money.

We predict that when individuals hold warm glow or instrumental motivations for volunteering, they will receive a private benefit from volunteering which directly derives from the amount of time they themselves give. Hence, the more strongly people hold these motivations, the more they will volunteer.

\footnotetext{
1 'Warm glow' captures positive feelings, like an improved self-image, but also a reduction in negative feelings, like guilt or social pressure (Andreoni, 1990).
} 
Given the mitigated support that the literature has found for each of these three theoretical models (Prouteau and Wolff, 2004), we follow Smith (1994) in adopting the perspective that the different models are complementary. This paper aims to examine the (relative) effects that holding these distinct types of motivations have on volunteering. We formulate three hypotheses:

H1: Information about motivations to volunteer contains additional explanatory power over socio-demographic characteristics in predicting the actual amount of volunteering.

H2: The stronger the warm glow and instrumental motivations, the larger the degree of volunteering.

H3: The influence of the motivation to contribute to a public good on the degree of volunteering is negligible in large populations.

According to Rose-Ackerman (1996), empirical work has not been very successful in providing hard evidence on the motivations for charitable giving. Bradsley (2000) notes that direct tests about the warm glow motive have been difficult to implement, because this hypothesis is compatible with many patterns of behaviour. In order to circumvent these issues and to study the simultaneous behavioural implications of different motivational influences, we will use direct survey information on stated motivations. 


\section{Description of the Data}

The data used in this paper originates from the first wave of the Survey of Health, Ageing and Retirement in Europe (SHARE), which was conducted in ten European countries in 2004. SHARE is a multidisciplinary database that contains micro data on health, socio-economic status and social and family networks of some 22,000 individuals of fifty years and over (Börsch-Supan et al., 2005). The dataset also contains responses of individuals who are below fifty years of age, as spouses are always interviewed irrelevant of their age. The mean age of the total sample is 64 years $(S D=9.95))^{2}$ It is obvious that this sample is only representative for the elderly, and not for the general population. This is no problem for our analysis, however, which will focus on the relationship between different motivations and the amount of volunteering at an individual level.

The SHARE dataset contains information on whether the respondents did or did not volunteer in the month before the interview, and if they volunteer, whether they do it almost monthly, weekly or daily. The answers to these questions are summarized in Table 1. On average, 14\% of the observed (elderly) European population engaged in voluntary or charity work in the month before they were interviewed. National averages range from $7 \%$ in Italy to $22 \%$ in the Netherlands. ${ }^{3}$

Insert Table 1 about here

\footnotetext{
2 The ten countries in release one of the first wave of SHARE were Denmark, Sweden, Austria, France, Germany, Switzerland, the Netherlands, Spain, Italy and Greece (Börsch-Supan et al., 2005). On average, the dataset contains 2,198 observations per country $(S D=660)$. Sweden has the largest number of observations $(2,954)$ while Switzerland has the lowest sample size (938). As volunteering drops sharply at extremely old age (Glass et al., 1995) and to ensure sample coherence, outliers were removed based on age. An observation was declared an age outlier if it lies outside of the interval [median $-2,5 \times \mathrm{SD}$; median $+2,5 \mathrm{x}$ SD]. Accordingly, observations younger than $36(0,1 \%$ of sample) or older than $89(1,2 \%$ of sample) were removed.

${ }^{3}$ In Spain and Greece the percentage of volunteers was only $2 \%$ and $3 \%$ respectively. As the resulting number of observations is too small to allow for a meaningful empirical analysis, we excluded Spain and Greece from our analysis.
} 
Apart from the large sample size, one key advantage of the SHARE dataset is that it contains an exhaustive set of socio-economic variables and thus allows the inclusion of nearly all socio-economic predictors identified in the literature. Even more important for our purposes, volunteers were also asked to indicate their motivations for volunteering. They could pick none, one, or more motives from the list displayed in Table 2. This results in a series of seven dummy variables, which measure subjective motivation. Enjoying volunteering and contributing to a useful cause are cited most often as reasons for volunteering. The items "because I feel obligated to do it" and "for personal achievement" are endorsed the least. ${ }^{4}$

The seven motivational items can be interpreted as proxies for the level of the three broader groups of motivations identified in the previous section. The answers "to meet other people", "because I enjoy it" and "to use my skills or to keep fit" are clearly indicators of volunteering to indirectly achieve a resultant benefit. They point to 'instrumental' reasons for volunteering. "Being needed" relates to the desire to conform to the norms and expectations of one's circle of acquaintances. If an individual volunteers because he "feels obligated", he does so to avoid negative feelings, like guilt, about not doing so. Both these items are indicative of a 'warm glow' motivation. Individuals who volunteer "to contribute something useful" state that they wish to contribute to a good or service which benefits the community at large. This item is an indicator of willingness to contribute to a 'public good'. It is difficult to provide an ex ante intuition about the final item, "for personal achievement". It can arguably be indicative of both the warm glow and the instrumental motivations.

\footnotetext{
${ }^{4}$ Since our sample is only representative for the elderly, it is of course impossible to extrapolate our findings about the relative importance of the different motivations to the general population. It has been found previously that older adults tend to be motivated to a greater extent by service or community obligation concerns and that both younger and older volunteers are more motivated by achieving outcomes that are related to interpersonal relationships than middle aged individuals (Okun et al., 1998; Omoto et al., 2000).
} 
Insert Table 2 about here

Exploratory factor analysis, using the principal component factoring technique, followed by a quartimax rotation, was employed to check more formally whether these three dimensions are present in the data. Following Fabrigar et al.'s (1999) recommendation, a number of oblique rotations were tried first. As correlations between factors were low (warm glow and instrumental: $r(2462)=.05, p<.05$; warm glow and public good: $r(2462)=.13, p<.01$; public good and instrumental $r(2462)=.20, p<.01)$, an orthogonal rotation was preferable for ease of interpretation (Rummel, 1970). Table 3 displays the factor loadings and the communalities for the different items. $58.4 \%$ of the total variance in the seven original items is explained by three common components. The final communality estimates are reasonably good, except for the items "because I feel obligated to do it" (0.13) and "for personal achievement" (0.10). Only respectively $18 \%$ and $14 \%$ of volunteers indicate these to be important motivations for volunteering. As a comparison, all other items received between $31 \%$ and $68 \%$ positive responses and their communalities ranged from 0.48 to 0.96 .

Insert Table 3 about here

Considering that the questionnaire was not especially set up for this kind of analysis, the results in Table 3 are rather satisfactory and confirm the presence of the three proposed underlying latent variables. Using the component score coefficient matrix, we can now calculate the motivational profile for each respondent. A motivational profile consists of a factor score for each of the three identified factors (or latent variables). As the analysis indicates that the factors are orthogonal, the factor scores can be interpreted as the strength of 
separate but coexisting motivations - linked to the three theoretical constructs described in the previous section.

A first look at Table 2 suggests that the data are well in line with our theoretical hypotheses. There is little difference in reported importance of the "to contribute something useful" item between the volunteers that donate less and more time. Concerning the warm glow items, patterns are in the expected direction. The more someone feels that she is needed or feels obligated, the more she will volunteer. For the instrumental motivations, the relationship appears to be quite strong and is in the expected direction for the "because I enjoy it" and "to use my skills or to keep fit" items. The relationship seems weaker and non-linear for the item "meeting other people". 5 Of course, the raw data in Table 2 may be misleading. Let us therefore now turn to a more refined multivariate analysis.

\section{Empirical Analysis}

We want to test our three hypotheses within an empirical model of the actual amount of volunteering. Since we only observe whether individuals do not volunteer or volunteer almost monthly, weekly or daily, our data are not linear but ordinal. Moreover since donations of time cannot be less than zero, the observed dependent variable is truncated at zero. As no truncated model for ordinal data is well established, and as we want to allow for different explanatory variables in the model of the decision about whether or not to volunteer on the one hand and the model of the decision about how much to volunteer on the other (Bergstrom et al., 1986),

\footnotetext{
${ }^{5}$ This might be due to a ceiling effect. Volunteering weekly might suffice to achieve respondents' need to meet people.
} 
we adapted the well known Tobit II model for truncated, continuous data by replacing the OLS regression in the second step by an Ordered Probit. The model then becomes:

$$
\begin{array}{ll}
y_{i}^{* *}=0 & \text { if } y_{i}^{*}=X_{i} \alpha+\varepsilon_{1, i} \leq 0 \\
y_{i}^{* *}=Z_{i} \beta+\varepsilon_{2, i} & \text { if } y_{i}^{*}=X_{i} \alpha+\varepsilon_{1, i}>0 \\
Y_{i}=j & \text { if } \quad A_{j-1} \leq y_{i}^{* *}<A_{j} ; A_{0}=-\infty, A_{J}=+\infty ; j \in[1, J]
\end{array}
$$

$Y_{i}$ is the observed discrete random variable that indicates which class of volunteering individual $i$ is in. $y_{i}{ }^{*}$ and $y_{i}^{* *}$ are the unobservable random variables equal to the amount of volunteering people respectively would like to do and actually do. The variables included and the coefficients estimated in the first and second stage are given by respectively $X_{i}$ and $Z_{i}$ and $\alpha$ and $\beta$. Both error terms $\varepsilon_{1, i} \sim N(0,1)$ and $\varepsilon_{2, i} \sim N(0,1)$ may be correlated. The $A_{j}$ represent the threshold values of $y_{i}^{* *}$.

The model was estimated by Heckman's (1976) procedure. To allow a tough test of our first hypothesis, we included in the model nearly all socio-economic variables that are found relevant in the literature. After excluding individuals who did not respond to all questions of interest, we were left with a subsample of 17,012 individuals of whom 2,464 had volunteered in the month before the interview took place.

To check robustness, different versions of the empirical model were estimated. Estimation results are summarised in Table 4. The selection step remains the same between versions. It includes all relevant socio-demographic variables and country dummies to control for the 
most important country specific effects. ${ }^{6,7}$ The second, quantity decision step differs between the models. In the first version, which serves as a baseline (1), the quantity step includes all relevant socio-economic variables and country dummies. In the second version (2), the factor scores, describing the motivational profile of the individual respondents, are included in addition to the socio-demographic variables. In order to avoid relying solely on the results of the factor analysis, we also estimated an alternative model (3) that contains the original motivational items as found in the SHARE database. Finally, to test the model's sensitivity to country differences, the central model was re-estimated including country by motivation cross-effects (4).

In all versions, both steps of the model perform significantly better than the null model on all traditionally used indicators. The inverse Mill's ratios are insignificant, suggesting that there is no strong selection effect. The results for the socio-economic variables largely replicate the established literature and remain largely unaffected by the inclusion of the motivational factors. ${ }^{8}$ Even though the list of socio-economic variables is very extensive, introducing the three motivational factors (model 2) constitutes a significant improvement over the model

\footnotetext{
${ }^{6}$ The literature describes health (Bowen et al., 2000) and community integration (Ryan et al., 2005) as important barriers to volunteering. To ensure that the global model is not only identified by the model assumptions, information about individuals' mental and physical health and proxies for their integration in their local communities was included in the first stage only. Specification test confirmed that these variables determine whether someone volunteers or not, but not how much time a volunteer donates.

${ }^{7}$ Sweden (the country with the largest number of observations) served as reference.

${ }^{8}$ We find an inverted-U age pattern for the decision about whether or not to volunteer. Respondents between 60 and 64 have the largest chance of being a volunteer. This peak comes at an older age than the one found by Menchik and Weisbrod (1987) and Prouteau and Wolff (2006), but is in line with the findings of Day and Devlin (1996). The peak might be explained by a "retirement shock" effect. Exchange theory suggests that people who have just retired, but who are unable to adjust to their new situation, use volunteering to replace psychic and social benefits formerly derived from paid employment (Midlarsky and Kahana, 1994). This effect would then gradually fade away as people get accustomed to their retirement. There is no influence of age on the amount of time a volunteer contributes. The results confirm Clotfelter's (1985) conclusion that there is a significant positive effect of available hours on number of hours volunteered. Living in smaller communities encourages volunteering. We find large marginal effects associated with education (see e.g. Day and Devlin, 1996; Prouteau and Wolff, 2006). A woman is equally likely to be a volunteer than a man, but male volunteers spend more time volunteering. Having children in the household increases the chances of being a volunteer (see also Bowman, 2004; Schiff, 1990). Our controls for health status and integration in the local community give the expected results.
} 
containing only socio-economic factors and country dummies $\left(\chi^{2}(3, N=2464)=98, p<.001\right)$. Adding (in model 3) the seven original motivational dummies to the baseline gives a similar result $\left(\chi^{2}(7, \mathrm{~N}=2464)=142, p<.001\right)$. These results firmly confirm our first hypothesis. Motivational components definitively hold explanatory power beyond that of the traditionally included socio-economic variables.

The second hypothesis states that stronger warm glow and instrumental motives should lead to a larger degree of volunteering. The third hypothesis implies that the marginal effect of the motivation to contribute to the public good on the number of hours donated should be small to non-existent. As can be seen in Table 4, all three motivational factors exert a statistically significant influence in model (2). However, the relative magnitudes of the marginal effects evaluated at the covariate means, displayed in Table 5 reveal that the influence of the instrumental motive factor and the warm glow factor is about three times as high as that of the public goods factor. Moreover, Table 4 shows that the significance level is higher for the instrumental $(p<.0001)$ and warm glow factors $(p<.0001)$ than for the public goods factor $(p<.05) . \quad \chi^{2}$ tests ((Train, 2003) indicate that, while it can not be rejected that the instrumental value and warm glow components' coefficients are equal $\left(\chi^{2}(1, N=2464)=2\right.$, NS), the effect of the public good factor is significantly smaller than both that of the instrumental $\left(\chi^{2}(1, N=2464)=16, p<.01\right)$ and warm glow $\left(\chi^{2}(1, N=2464)=6, p<.05\right)$ factor. The third model specification (3), in which individual items are included, is even more transparent. Both warm glow items and two out of the three instrumental items significantly predict the amount of time donated. The public good item has no significant influence. A chisquare test does not reject the hypothesis that the coefficients of the items "because I enjoy it" and "to use my skills or to keep fit" are equal, those of "because I am needed" and "because I feel obligated to do it" are equal and that there is no influence of the items "to meet other 
people" and "to contribute something useful" $\left(\chi^{2}(4, \mathrm{~N}=2464)=4, \mathrm{NS}\right)$. These more detailed results confirm our theoretical predictions. Warm glow and instrumental items exert a significant influence on the amount of volunteering time, while an increased desire to contribute to a public good has no such influence.

In order to test the model's sensitivity to country differences, the central model was reestimated without country dummies. ${ }^{9}$ While this significantly worsens the model performance $\left(\chi^{2}(7, N=2464)=66, p<.001\right)$, parameter estimates for the other variables are robust. To further test the robustness of our results for country effects, model (2) was extended by adding all country by motivation cross-effects as explanatory variables. The estimates of the resulting model (4), which performs significantly better than that without cross-effects $\left(\chi^{2}(21\right.$, $N=2464)=36, p<.05$ ), give further support to our assertions. ${ }^{10}$ Adding country by motivation cross-effects causes the effect of the public good motivation for the European sample as a whole to become insignificant, while the estimated impact of the warm glow and instrumental motivation becomes more important. Examination of the cross-effects reveals that only in Germany the strength of the public good motivation does exert an influence on volunteering frequency.

Insert Table 4 about here

Insert Table 5 about here

\footnotetext{
${ }^{9}$ These results are not shown in Table 4, but can be obtained from the authors on request.

${ }^{10}$ While all cross-effects were included in the model, only marginally significant cross-effects are displayed in Table 4. Full results are available from the authors.
} 
In summary, we can state that the amount of volunteering chosen by volunteers is significantly affected by the level of warm glow and instrumental motivations. A higher stated importance of contributing to a public good has a small to insignificant impact on the actual amount of time supplied by volunteers.

\section{Discussion}

Direct survey information on stated motivations adds significantly to the explanation of the amount of time volunteers choose to donate, over and above socio-economic variables. Moreover, the pattern of our empirical results makes sense in the light of theoretical considerations. These findings complement those of Smith et al. (1995) and Schokkaert \& Van Ootegem (2000) who came to a similar conclusion for money donations to charitable causes.

When volunteering yields larger private benefits for the individual, this does lead to an increased volunteering frequency. However, individuals who are more strongly motivated by a desire to contribute to the public good do not necessarily volunteer more. This is suggestive evidence for Andreoni's (1989) argument that even if donors care about the level of the public good, free-riding makes this concern an implausible explanation for the pattern of donations and volunteering which is observed. "Mixed altruism" is a feature of the real world, in which individuals are driven by different motivations.

The fact that the instrumental motivation significantly influences the volunteering frequency implies a decreased substitutability between gifts of money and gifts of time. One can contribute to a public good and even get warm glow and prestige by donating money. 
However, the instrumental benefits of volunteering are generally not obtainable by giving cash to charitable causes.

The results of this paper may also contribute to explaining the diverse findings in the literature on volunteers' reactions to government expenditures (e.g. Day and Devlin, 1996; Duncan, 1999; Menchik and Weisbrod, 1987). Our results imply that the mix of motivations in the relevant population will determine individuals' reactions to government spending. When volunteers are only motivated by a desire to contribute to a public good, their own and the government's provision of this good are perfect substitutes. However, if volunteers are sufficiently motivated by warm glow or instrumental motivations, little crowding out should occur after a change in government expenditures. If government spending enables volunteers to better achieve their warm glow or instrumental goals by making their time donations more effective, it may even cause ‘crowding in' (Prouteau and Wolff, 2008; Schiff, 1985).

Our finding that the 'public good' or 'pure altruism' motivation for volunteering, which has been shown to be of importance at the level of neural activity (Harbaugh et al., 2007), may be of little consequence in real behaviour parallels several findings from psychology. Indeed, Stahl and Haruvy (2006) find that contributions to a public good dwindle as group size increases. They suggest a perceived reduced effect of one individual's contribution on the level of public good as whole and diffusion of responsibility as explanations for this decrease. When individuals know that many others are present, they do not bear the full burden of responsibility as individuals (Darley and Latane, 1968), and they expect that someone else will bear the necessary sacrifice.

Individually describing and showing small, identifiable beneficiary groups may make the 
target more vivid and hence redirect contributors' focus from their contribution to the public good to the warm glow they will receive from their contribution. This is illustrated by Small \& Loewenstein's (2003) finding that people give more to more vividly described, identifiable victims than to statistically described victims, even though the statistically described victims are more numerous and contributions to their cause would lead to a greater marginal benefit than contributions to the identifiable victims. Thus, in accordance with our findings, Small \& Loewenstein (2003) show that people value warm glow more than contributing to the public good, as donating to the more vividly described, identifiable victims yields relatively more warm glow while donating to the statistically described victims would lead to a larger increase in public good.

An alternative to redirecting peoples' attention away from their public good motivation could be to counteract feelings of diffusion of responsibility. One possibility is targeting charitable requests to small sets of donors, making them aware that they belong to a limited group of possible contributors. This principle was demonstrated by Barron and Yechiam (2002), who found that recipients were more likely to comply to a private email request when they are the only person in the 'To' box than when the email was addressed to a number of people simultaneously.

Finally, donors' underlying motivations have practical implications for non-profit organizations (Clary et al., 1992). 'Selling' volunteering by focusing on the potential impact of the volunteer on the promoted good cause may get a lot of people to think that the cause is worth volunteering for, but result in little extra volunteering. Instead, volunteer coordinators should look at what private benefits their target group seeks to gain from the volunteering exchange. When designing their organisational structure and the content of volunteers' jobs, 
non-profit managers should make sure that there is a right balance between being productive in creating the public good and creating the private benefits that volunteers seek. If instrumental considerations dominate, non-profit managers should focus on communicating what volunteering can result in, besides helping others. Why and how volunteering makes volunteers feel good about themselves should be emphasized to satisfy peoples' warm glow motivation. Encouraging volunteers to work in close contact with the beneficiaries may prove to be a particularly effective strategy to increase their warm glow feelings. If people want others to view them as good and generous, solicitation by friends and neighbours will be effective in increasing contributions (Bowman, 2004; Freeman, 1997).

While the SHARE dataset offers several advantages, its main limitation is in the measurement of the motivations for volunteering. It does not contain information on the hypothetical motivations of non-volunteers and therefore does not allow analysing the influence of the three groups of motives on the decision to volunteer or not. In addition, the level of detail on motivations is limited, which may induce measurement error in the self reported motives. Respondents who are slightly motivated by for example moral obligation might give the same answer as those who are highly motivated by it. Still, given the size of the dataset, the fact that basic tendencies seem to be captured by these simple responses and the presence of sufficient variation in the items, we feel that the level of detail provided by the SHARE dataset suffices to accomplish our goal of exploring the importance of motivations in explaining volunteering. More detailed information about volunteers' motivations is necessary if one wants to draw stronger conclusions.

Finally, the SHARE-data are not representative for the overall population. However, while it is likely that the average importance of the different motivations differs between age groups, 
there are no strong reasons to suspect that the influence of these motivations on the amount of time donated should also differ.

\section{6. $\underline{\text { Conclusion }}$}

The goal of this paper was to further investigate the role of volunteers' motivations in explaining the time donated to charitable causes. While previous work often concentrates either on the warm glow, the public good or the instrumental explanation for volunteering, we studied the simultaneous effect of different motivational influences by incorporating direct information on motivations into the models. Using data from eight European countries, we showed that the inclusion of direct information on motivations increases the model's explanatory power beyond that of the traditionally included socio-economic variables. In addition, our results suggest that the more people hold warm glow and instrumental motivations, the larger the degree of volunteering. However, as theoretically predicted by public goods theory, the influence of the motivation to contribute to a public good on the degree of volunteering is shown to be quite limited in large populations. When explaining volunteering, economic and psychological approaches are deeply complementary. 


\section{Acknowledgement}

This paper uses data from Wave 1 of SHARE 2004. SHARE data collection in 2004 was primarily funded by the European Commission through its 5th and 6th framework programmes (project numbers QLK6-CT-2001- 00360; RII-CT- 2006-062193; CIT5-CT2005-028857). Additional funding by the US National Institute on Aging (grant numbers U01 AG09740-13S2; P01 AG005842; P01 AG08291; P30 AG12815; Y1-AG-4553-01; OGHA 04-064; R21 AG025169) as well as by various national sources is gratefully acknowledged (see http://www.share-project.org for a full list of funding institutions). 


\section{References}

Andreoni, J. (1989). Giving with impure altruism - applications to charity and ricardian equivalence. Journal of Political Economy, 97, 1447-1458.

Andreoni, J. (1990). Impure altruism and donations to public-goods - a theory of warm-glow giving. Economic Journal, 100, 464-477.

Barron, G., \& Yechiam, E. (2002). Private e-mail requests and the diffusion of responsibility. Computers in Human Behavior, 18, 507-520.

Bergstrom, T., Blume, L., \& Varian, H. (1986). On the private provision of public-goods. Journal of Public Economics, 29, 25-49.

Börsch-Supan, A., Brugiavini, A., Jürges, H., Mackenbach, J., Siegrist, J., \& Weber, G. (Eds.) (2005). Health, ageing and retirement in europe. First results from the survey of health, ageing and retirement in europe. Mannheim: MEA.

Bowen, D. J., Andersen, M. R., \& Urban, N. (2000). Volunteerism in a community-based sample of women aged 50 to 80 years. Journal of Applied Social Psychology, 30, 18291842.

Bowman, W. (2004). Confidence in charitable institutions and volunteering. Nonprofit and Voluntary Sector Quarterly, 33, 247-270.

Bradsley, N. (2000). Control without deception: Individual behaviour in free-riding experiments revisited. Experimental Economics, 3, 215-240.

Brudney, J. L. (1990). Fostering volunteer programs in the public sector: Planning, initiating, and managing voluntary activities. San Francisco: Jossey-Bass.

Clary, E. G., Snyder, M., \& Ridge, R. (1992). Volunteers' motivations: A functional strategy for the recruitment, placement, and retention of volunteers. Nonprofit Management and Leadership, 2, 333-350. 
Clotfelter, C. T. (1985). Federal tax policy and charitable giving. Chicago: University of Chicago press.

Darley, J. M., \& Latane, B. (1968). Bystander intervention in emergencies: Diffusion of responsibility. Journal of Personality and Social Psychology, 8, 377-383.

Davis-Smith, J. (1998). The 1997 national survey of volunteering. London: Institute for Volunteering Research.

Day, K. M., \& Devlin, R. A. (1996). Volunteerism and crowding out: Canadian econometric evidence. Canadian Journal of Economics-Revue Canadienne D Economique, 29, 37-53.

Day, K. M., \& Devlin, R. A. (1998). The payoff to work without pay: Volunteer work as an investment in human capital. Canadian Journal of Economics-Revue Canadienne D Economique, 31, 1179-1191.

Duncan, B. (1999). Modeling charitable contributions of time and money. Journal of Public Economics, 72, 213-242.

Eurobarometer (2007). European social reality: Special Eurobarometer 273/Wave 66.3.

Fabrigar, L. R., Wegener, D. T., MacCallum, R. C., \& Strahan, E. J. (1999). Evaluating the use of exploratory factor analysis in psychological research. Psychological Methods, 4, 272-299.

Freeman, R. B. (1997). Working for nothing: The supply of volunteer labor. Journal of Labor Economics, 15, S140-S166.

Glaeser, E. G., Laibson, D., \& Sacerdote, B. (2002). The economic approach to social capital. Economic Journal, 112, 437-458.

Glass, T. A., Seeman, T. E., Herzog, A. R., Kahn, R., \& Berkman, L. (1995). Change in productive activity in late adulthood: Macarthur studies of successful aging. Journals of Gerontology: Series B: Psychological Sciences and Social Sciences, 50B, S65-S76. 
Harbaugh, W. T., Mayr, U., \& Burghart, D. R. (2007). Neural responses to taxation and voluntary giving reveal motives for charitable donations. Science, 316, 1622-1625.

Heckman, J. J. (1976). Common structure of statistical-models of truncation, sample selection and limited dependent variables and a simple estimator for such models. Annals of Economic and Social Measurement, 5, 475-492.

Lynn, P., \& Davis-Smith, J. (1991). Voluntary action research: The 1991 national survey of voluntary activity in the uk. London: SCPR.

Marwell, G. (1982). Altruism and the problem of collective action. In V. J. Derlaga, \& J. Grzelak (Eds.), Living with other people: Theories and research on cooperation and helping behavior (pp. 207-236). New York: Academic Press.

Menchik, P. L., \& Weisbrod, B. A. (1987). Volunteer labour supply. Journal of Public Economics, 32, 159-183.

Midlarsky, E., \& Kahana, E. (1994). Altruism in later life: Sage Publications.

Okun, M. A., Barr, A., \& Herzog, A. R. (1998). Motivation to volunteer by older adults: A test of competing measurement models. Psychology and Aging, 13, 608-621.

Omoto, A. M., Snyder, M., \& Martino, S. C. (2000). Volunteerism and the life course: Investigating age-related agendas for action. Basic and Applied Social Psychology, 22, 181-197.

Piliavin, J. A., \& Charng, H. W. (1990). Altruism: A review of recent theory and research. Annual Review of Sociology, 16, 27-65.

Prouteau, L., \& Wolff, F.-C. (2004). Relational goods and associational participation. Annals of Public and Cooperative Economics, 75, 431-463.

Prouteau, L., \& Wolff, F.-C. (2006). Does volunteer work pay off in the labor market? The Journal of Socio-Economics, 35, 992-1013. 
Prouteau, L., \& Wolff, F.-C. (2008). On the relational motive for volunteer work. Journal of Economic Psychology, 29, 314-335.

Rose-Ackerman, S. (1996). Altruism, nonprofits, and economic theory. Journal of Economic Literature, 34, 701-728.

Rummel, R. J. (1970). Applied factor analysis. Evanston: Northwestern University Press.

Ryan, V. D., Agnitsch, K. A., Zhao, L. J., \& Mullick, R. (2005). Making sense of voluntary participation: A theoretical synthesis. Rural Sociology, 70, 287-313.

Samuelson, P. (1954). The pure theory of public expenditure. Review of Economics and Statistics, 36, 387-389.

Schiff, J. (1985). Does government spending crowd out charitable contributions. National Tax Journal, 38, 535-546.

Schiff, J. (1990). Charitable giving and government policy. An economic analysis. New York: Greenwood Press.

Schokkaert, E. (2006). The empirical analysis of transfer motives. In S.-C. Kolm, \& J. M. Ythier (Eds.), Handbook of the economics of giving, altruism and reciprocity. (Volume I) (pp. 127-181). Handbooks in economics. New York: Elsevier Science.

Schokkaert, E., \& Van Ootegem, L. (2000). Preference variation and private donations. In L.A. Gérard-Varet, K. S-C., \& Y. J.M. (Eds.), The economics of reciprocity, giving and altruism (pp. 78-95). London: Macmillan.

Schram, V. R., \& Dunsing, M. M. (1981). Influences on married women's volunteer work participation. Journal of Consumer Research, 7, 372-379.

Small, D. A., \& Loewenstein, G. (2003). Helping a victim or helping the victim: Altruism and identifiability. Journal of Risk and Uncertainty, 26, 5-16.

Smith, D. H. (1994). Determinants of voluntary association participation and volunteering: A literature review. Nonprofit and Voluntary Sector Quarterly, 23, 243-263. 
Smith, V. H., Kehoe, M. R., \& Cremer, M. E. (1995). The private provision of public-goods: Altruism and voluntary giving. Journal of Public Economics, 58, 107-126.

Stahl, D. O., \& Haruvy, E. (2006). Other-regarding preference: Egalitarian warm glow, empathy, and group size. Journal of Economic Behavior \& Organization, 61, 20-41.

Train, K. E. (2003). Discrete choice methods with simulation. Cambridge: Cambridge University Press.

Weisbrod, B. (1975). Toward a theory of the voluntary sector in a three-sector economy. In E. S. Phelps (Ed.), Altruism, morality and economic theory. New York: Russell Sage Foundation.

Wilson, J. (2000). Volunteering. Annual Review of Sociology, 26, 215-240. 
Table 1

Volunteering in Europe

\begin{tabular}{lrrrr}
\hline Country & Voluntary work & \multicolumn{3}{c}{ Frequency } \\
\cline { 3 - 5 } & & Less than weekly & Almost weekly & Almost daily \\
\hline Europe & $14 \%$ & $37 \%$ & $48 \%$ & $15 \%$ \\
Austria & $9 \%$ & $54 \%$ & $43 \%$ & $3 \%$ \\
Germany & $11 \%$ & $37 \%$ & $47 \%$ & $16 \%$ \\
Sweden & $18 \%$ & $45 \%$ & $41 \%$ & $14 \%$ \\
The Netherlands & $22 \%$ & $24 \%$ & $61 \%$ & $15 \%$ \\
Italy & $7 \%$ & $37 \%$ & $45 \%$ & $18 \%$ \\
France & $13 \%$ & $36 \%$ & $42 \%$ & $22 \%$ \\
Denmark & $18 \%$ & $40 \%$ & $49 \%$ & $11 \%$ \\
Switzerland & $14 \%$ & $46 \%$ & $41 \%$ & $13 \%$ \\
\hline
\end{tabular}


Table 2

Volunteering Motivations

\begin{tabular}{|c|c|c|c|}
\hline Item & Mean & Mean by volunteering frequency & Clas sification \\
\hline To meet other people & $40 \%$ & & Instrumental \\
\hline less than weekly & & $35 \%$ & \\
\hline almost weekly & & $44 \%$ & \\
\hline almost daily & & $40 \%$ & \\
\hline Because I enjoy it & $67 \%$ & & Instrumental \\
\hline less than weekly & & $58 \%$ & \\
\hline almost weekly & & $72 \%$ & \\
\hline almost daily & & $76 \%$ & \\
\hline To use my skills or to keep fit & $32 \%$ & & Instrumental \\
\hline less than weekly & & $21 \%$ & \\
\hline almost weekly & & $38 \%$ & \\
\hline almost daily & & $40 \%$ & \\
\hline To contribute something useful & $67 \%$ & & Public good \\
\hline less than weekly & & $63 \%$ & \\
\hline almost weekly & & $70 \%$ & \\
\hline almost daily & & $68 \%$ & \\
\hline Because I am needed & $46 \%$ & & Warm glow \\
\hline less than weekly & & $39 \%$ & \\
\hline almost weekly & & $49 \%$ & \\
\hline almost daily & & $53 \%$ & \\
\hline Because I feel obligated to do it & $18 \%$ & & Warm glow \\
\hline less than weekly & & $15 \%$ & \\
\hline almost weekly & & $19 \%$ & \\
\hline almost daily & & $22 \%$ & \\
\hline For personal achievement & $14 \%$ & & I \\
\hline less than weekly & & $11 \%$ & \\
\hline almost weekly & & $15 \%$ & \\
\hline almost daily & & $19 \%$ & \\
\hline
\end{tabular}


Table 3

Factor loadings and communalities

\begin{tabular}{lrrrr}
\hline Item & \multicolumn{2}{c}{ Factor loadings } & Communalities \\
\cline { 2 - 4 } & Instrumental & Warm glow & Public good & \\
\hline To meet other people & 0.78 & -0.07 & -0.13 & 0.62 \\
To contribute something us eful & 0.09 & 0.01 & 0.94 & 0.89 \\
For personal achievement & 0.27 & 0.03 & 0.17 & 0.10 \\
Because I am needed & 0.19 & 0.95 & 0.01 & 0.95 \\
Because I enjoy it & 0.69 & -0.04 & -0.11 & 0.49 \\
To use my skills or to keep fit & 0.59 & 0.14 & 0.33 & 0.48 \\
Because I feel obligated to do it & -0.06 & 0.36 & 0.01 & 0.13 \\
\hline
\end{tabular}


Table 4

Estimation results

\begin{tabular}{|c|c|c|c|c|c|c|c|c|c|c|c|c|c|c|c|}
\hline \multirow[t]{3}{*}{ Variables } & \multicolumn{3}{|c|}{ Decision } & \multicolumn{12}{|c|}{ Amount } \\
\hline & \multirow[b]{2}{*}{ coef } & \multirow{2}{*}{\multicolumn{2}{|c|}{$\mathrm{t}$-value }} & \multicolumn{3}{|c|}{ (1) } & \multicolumn{3}{|c|}{ (2) } & \multicolumn{3}{|c|}{ (3) } & \multicolumn{3}{|c|}{ (4) } \\
\hline & & & & coef & & $\frac{t \text {-value }}{2}$ & coef & & $\overline{t \text {-value }}$ & coef & & $\overline{t \text {-value }}$ & coef & & t-value \\
\hline Constant & -1.443 & $* *$ & -13.19 & 0.003 & & 0.01 & -0.067 & & -0.15 & -0.564 & & -1.24 & -0.039 & & -0.09 \\
\hline Cut point distance & & & & 1.442 & $* *$ & 40.98 & 1.478 & $* *$ & 40.92 & 1.495 & $* *$ & 40.84 & 1.490 & $* *$ & 40.91 \\
\hline \multicolumn{16}{|l|}{ Marital status } \\
\hline Married & Ref & & & Ref & & & Ref & & & Ref & & & Ref & & \\
\hline Never married & -0.033 & & -0.52 & 0.243 & $*$ & 1.94 & 0.227 & $*$ & 1.80 & 0.237 & $*$ & 1.88 & 0.219 & $*$ & 1.72 \\
\hline Divorced & 0.004 & & 0.06 & 0.273 & $* *$ & 2.57 & 0.247 & $* *$ & 2.31 & 0.242 & $* *$ & 2.25 & 0.233 & $* *$ & 2.17 \\
\hline Widowed & 0.001 & & 0.03 & 0.002 & & 0.02 & -0.020 & & -0.21 & -0.030 & & -0.31 & -0.025 & & -0.26 \\
\hline Not married, living with partner & -0.314 & $* *$ & -3.40 & -0.030 & & -0.15 & -0.077 & & -0.37 & -0.070 & & -0.34 & -0.056 & & -0.27 \\
\hline Number of children $<18 \mathrm{y}$ old & 0.126 & $* *$ & 3.35 & 0.025 & & 0.37 & 0.044 & & 0.65 & 0.050 & & 0.73 & 0.047 & & 0.69 \\
\hline Female & -0.042 & & -1.45 & -0.152 & $* *$ & -2.74 & -0.161 & $* *$ & -2.89 & -0.160 & $* *$ & -2.84 & -0.164 & $* *$ & -2.91 \\
\hline \multicolumn{16}{|l|}{ Age } \\
\hline Between 35 and 49 & 0.098 & & 1.25 & -0.036 & & -0.24 & -0.078 & & -0.52 & -0.032 & & -0.21 & -0.050 & & -0.33 \\
\hline Between 50 and 54 & Ref & & & Ref & & & Ref & & & Ref & & & Ref & & \\
\hline Between 55 and 59 & 0.081 & * & 1.93 & 0.014 & & 0.17 & 0.007 & & 0.09 & 0.017 & & 0.21 & 0.008 & & 0.10 \\
\hline Between 60 and 64 & 0.100 & $* *$ & 2.12 & 0.087 & & 0.97 & 0.096 & & 1.07 & 0.110 & & 1.22 & 0.093 & & 1.02 \\
\hline Between 65 and 69 & 0.048 & & 0.86 & 0.063 & & 0.60 & 0.070 & & 0.66 & 0.106 & & 0.99 & 0.068 & & 0.64 \\
\hline Between 70 and 79 & -0.057 & & -1.01 & 0.112 & & 1.05 & 0.105 & & 0.98 & 0.138 & & 1.28 & 0.096 & & 0.88 \\
\hline Between 80 and 89 & -0.363 & $* *$ & -4.60 & -0.017 & & -0.10 & -0.005 & & -0.03 & 0.012 & & 0.07 & -0.021 & & -0.12 \\
\hline \multicolumn{16}{|l|}{ Occupational status } \\
\hline Retired & 0.273 & $* *$ & 6.11 & 0.371 & $* *$ & 3.91 & 0.370 & $* *$ & 3.86 & 0.381 & $* *$ & 3.96 & 0.374 & $* *$ & 3.88 \\
\hline Working fulltime & Ref & & & Ref & & & Ref & & & Ref & & & Ref & & \\
\hline Between $1 / 3$ and $2 / 3$ of fulltime & 0.204 & $* *$ & 3.25 & 0.288 & $* *$ & 2.45 & 0.309 & $* *$ & 2.61 & 0.314 & $* *$ & 2.64 & 0.315 & $* *:$ & 2.65 \\
\hline Less than $1 / 3$ of fulltime & 0.275 & $* *$ & 2.85 & 0.179 & & 1.00 & 0.212 & & 1.18 & 0.248 & & 1.37 & 0.193 & & 1.07 \\
\hline Unemployed & 0.235 & $* *$ & 3.05 & 0.329 & $* *$ & 2.22 & 0.344 & $* *$ & 2.32 & 0.353 & $* *$ & 2.36 & 0.363 & $* *$ & 2.42 \\
\hline Disabled & 0.212 & $* *$ & 2.56 & 0.512 & $* *$ & 3.47 & 0.492 & $* *$ & 3.32 & 0.510 & $* *$ & 3.44 & 0.504 & $* *$ & 3.39 \\
\hline Homemaker & 0.336 & $* *$ & 5.67 & 0.417 & $* *$ & 3.33 & 0.406 & $* *$ & 3.21 & 0.428 & $* *$ & 3.38 & 0.411 & $* *$ & 3.23 \\
\hline Other job situation & 0.313 & $* *$ & 3.01 & 0.723 & $* *$ & 3.85 & 0.742 & $* *$ & 3.92 & 0.775 & $* *$ & 4.09 & 0.763 & $* *$ & 3.99 \\
\hline Has more than one job & 0.118 & $*$ & 1.84 & 0.010 & & 0.09 & 0.048 & & 0.41 & 0.055 & & 0.47 & 0.045 & & 0.38 \\
\hline \multicolumn{16}{|l|}{ Looks after grandchildren } \\
\hline Daily & -0.080 & & -1.13 & 0.047 & & 0.32 & -0.001 & & 0.00 & -0.003 & & -0.02 & 0.035 & & 0.23 \\
\hline Weekly & 0.138 & $* *$ & 3.35 & 0.110 & & 1.43 & 0.082 & & 1.06 & 0.073 & & 0.95 & 0.079 & & 1.02 \\
\hline Monthly & 0.089 & $*$ & 1.91 & -0.057 & & -0.67 & -0.077 & & -0.90 & -0.075 & & -0.88 & -0.068 & & -0.79 \\
\hline Less & 0.126 & $* *$ & 3.05 & -0.125 & & -1.62 & -0.143 & $*$ & -1.84 & -0.150 & $*$ & -1.93 & -0.145 & $*$ & -1.86 \\
\hline Never & Ref & & & Ref & & & Ref & & & Ref & & & Ref & & \\
\hline \multicolumn{16}{|l|}{ Area } \\
\hline Big city & Ref & & & Ref & & & Ref & & & Ref & & & Ref & & \\
\hline Suburbs & 0.001 & & 0.03 & -0.008 & & -0.09 & 0.005 & & 0.06 & 0.012 & & 0.13 & 0.000 & & 0.00 \\
\hline Larrge town & 0.099 & $* *$ & 2.05 & 0.071 & & 0.77 & 0.069 & & 0.73 & 0.079 & & 0.84 & 0.063 & & 0.66 \\
\hline Small town & 0.127 & $* *$ & 2.70 & 0.003 & & 0.04 & 0.023 & & 0.25 & 0.036 & & 0.38 & 0.017 & & 0.18 \\
\hline Rural & 0.209 & $* *$ & 4.50 & -0.048 & & -0.49 & -0.040 & & -0.41 & -0.033 & & -0.34 & -0.026 & & -0.27 \\
\hline \multicolumn{16}{|l|}{ Education } \\
\hline No education & -0.353 & $* *$ & -3.29 & -0.222 & & -0.94 & -0.181 & & -0.76 & -0.109 & & -0.46 & -0.195 & & -0.82 \\
\hline Lower education & -0.289 & $* *$ & -6.64 & -0.078 & & -0.77 & -0.076 & & -0.74 & -0.076 & & -0.75 & -0.092 & & -0.90 \\
\hline $\begin{array}{l}\text { Lower technical education/ } \\
\text { four years of high school }\end{array}$ & -0.131 & $* *$ & -3.67 & -0.153 & $* *$ & -2.15 & -0.152 & $* *$ & -2.13 & -0.149 & $* *$ & -2.07 & -0.161 & $* *$ & -2.22 \\
\hline Six years of high school & Ref & & & Ref & & & Ref & & & Ref & & & Ref & & \\
\hline Professional bachelor degree & 0.076 & & 0.90 & 0.158 & & 1.03 & 0.212 & & 1.37 & 0.193 & & 1.25 & 0.198 & & 1.27 \\
\hline University master degree & 0.236 & $* *$ & 6.95 & 0.028 & & 0.38 & 0.020 & & 0.27 & 0.013 & & 0.18 & -0.006 & & -0.08 \\
\hline 3 th cycle university degree, phd & 0.540 & $* *$ & 3.41 & 0.651 & $* *$ & 2.37 & 0.582 & $=$ & 2.11 & 0.602 & $* *$ & 2.17 & 0.599 & $* *$ & 2.14 \\
\hline
\end{tabular}


Table 4 (continued)

\begin{tabular}{|c|c|c|c|c|c|c|c|c|c|c|c|c|c|c|c|}
\hline \multirow[t]{3}{*}{ Variables } & \multicolumn{3}{|c|}{ Decision } & \multicolumn{12}{|c|}{ Amount } \\
\hline & \multirow{2}{*}{\multicolumn{2}{|c|}{ coef }} & \multirow[b]{2}{*}{$\mathrm{t}$-value } & \multicolumn{3}{|c|}{$(1)$} & \multicolumn{3}{|c|}{$(2)$} & \multicolumn{3}{|c|}{ (3) } & \multicolumn{3}{|c|}{ (4) } \\
\hline & & & & coef & & $\mathrm{t}$-value & coef & & $\mathrm{t}$-value & coef & & $t$-value & coef & & -value \\
\hline Ln(gr. personal income) & 0.004 & & 0.76 & -0.015 & & -1.63 & -0.016 & $*$ & -1.71 & -0.018 & $*$ & -1.85 & $-0.016 *$ & $*$ & -1.69 \\
\hline $\operatorname{Ln}($ gr. other household income) & 0.005 & & 0.93 & -0.008 & & -0.70 & -0.007 & & -0.60 & -0.009 & & -0.74 & -0.009 & & -0.77 \\
\hline \multicolumn{16}{|l|}{ Self reported health } \\
\hline Very good self reported health & 0.033 & & 1.00 & & & & & & & & & & & & \\
\hline Good self reported health & Ref & & & & & & & & & & & & & & \\
\hline Fair self reported health & -0.135 & $* *$ & -4.05 & & & & & & & & & & & & \\
\hline Bad self reported health & -0.277 & $* *$ & -4.17 & & & & & & & & & & & & \\
\hline Very bad self reported health & -0.751 & $* *$ & -4.35 & & & & & & & & & & & & \\
\hline Depression (Euro-D scale) & -0.012 & * & -1.69 & & & & & & & & & & & & \\
\hline 2 or more health symptoms & 0.119 & $* *$ & 3.82 & & & & & & & & & & & & \\
\hline 3 or more mobility limitations & -0.020 & & -0.46 & & & & & & & & & & & & \\
\hline Daily living activities limitations & -0.050 & & -0.83 & & & & & & & & & & & & \\
\hline Instr. daily living limitations & -0.129 & $* *$ & -2.66 & & & & & & & & & & & & \\
\hline Car ownership & 0.125 & $* *$ & 4.74 & 0.053 & & 0.93 & 0.065 & & 1.14 & 0.064 & & 1.12 & 0.070 & & 1.23 \\
\hline \multicolumn{16}{|l|}{ Integration in local community } \\
\hline Lives in community $>=5$ years & 0.219 & $* *$ & 4.05 & & & & & & & & & & & & \\
\hline Is an immigrant & -0.214 & $* *$ & -4.39 & & & & & & & & & & & & \\
\hline \multicolumn{16}{|l|}{ Country dummies } \\
\hline Austria & -0.524 & $* *$ & -9.61 & -0.455 & $5 * *$ & -3.14 & -0.377 & $* * ;$ & -2.59 & -0.491 & $* *$ & -3.31 & $-0.320 *$ & $* *$ & -2.12 \\
\hline Germany & -0.444 & $* *$ & -9.26 & 0.072 & & 0.58 & 0.079 & & 0.62 & 0.041 & & 0.32 & 0.087 & & 0.68 \\
\hline Sweden & Ref & & & Ref & & & Ref & & & Ref & & & Ref & & \\
\hline The Netherlands & 0.088 & $* *$ & 2.04 & 0.377 & $7 * *$ & 4.88 & 0.404 & $* *$ & 5.15 & 0.354 & $* *$ & 4.50 & $0.422 * *$ & $* *$ & 5.32 \\
\hline Italy & -0.569 & $* *$ & -10.67 & 0.113 & & 0.77 & 0.314 & $* *$ & 2.03 & 0.303 & $* *$ & 2.00 & $0.533 *$ & $* *$ & 3.05 \\
\hline France & -0.182 & $* *$ & -3.37 & 0.233 & $3 * *$ & 2.21 & 0.293 & $* *$ & 2.71 & 0.287 & $* *$ & 2.62 & $0.287 *$ & $* * ;$ & 2.63 \\
\hline Denmark & -0.122 & $* *$ & -2.46 & 0.067 & & 0.74 & 0.037 & & 0.37 & 0.052 & & 0.55 & 0.065 & & 0.68 \\
\hline Switzerland & -0.273 & $* *$ & -4.33 & -0.080 & & -0.62 & -0.020 & & -0.19 & -0.048 & & -0.36 & -0.026 & & -0.19 \\
\hline Inverse Mills' ratio & & & & 0.106 & & 0.46 & 0.129 & & 0.56 & 0.172 & & 0.74 & 0.128 & & 0.55 \\
\hline \multicolumn{16}{|l|}{ Motives } \\
\hline Intrumental factor & & & & & & & 0.191 & $* *=$ & 7.82 & & & & $0.261 *$ & $* * ;$ & 5.03 \\
\hline Public good factor & & & & & & & 0.047 & $* *$ & 2.00 & & & & 0.032 & & 0.63 \\
\hline Warm glow factor & & & & & & & 0.136 & $* *$ & 5.82 & & & & $0.182 *$ & $* * ;$ & 3.43 \\
\hline To meet other people & & & & & & & & & & -0.072 & & -1.40 & & & \\
\hline To contribute something useful & & & & & & & & & & 0.037 & & 0.73 & & & \\
\hline For personal achievement & & & & & & & & & & 0.161 & $* *$ & 2.19 & & & \\
\hline Because I am needed & & & & & & & & & & 0.194 & $* *$ & 3.96 & & & \\
\hline Because I enjoy it & & & & & & & & & & 0.348 & $* *$ & 6.44 & & & \\
\hline To use my skills or to keep fit & & & & & & & & & & 0.264 & $* *$ & 4.91 & & & \\
\hline Because I feel obligated to do it & & & & & & & & & & 0.219 & $* *$ & 3.48 & & & \\
\hline \multicolumn{16}{|l|}{ Cross-effects } \\
\hline Warm glow x Austria & & & & & & & & & & & & & $-0.187 *$ & * & -1.77 \\
\hline Instrumental x Germany & & & & & & & & & & & & & $-0.155 *$ & $*$ & -1.79 \\
\hline Public good x Germany & & & & & & & & & & & & & $0.168 *$ & $* *$ & 2.05 \\
\hline Instrumental x Netherlands & & & & & & & & & & & & & $-0.125 *$ & $*$ & -1.79 \\
\hline Instrumental x Denmark & & & & & & & & & & & & & $-0.149 *$ & $*$ & -1.79 \\
\hline \# observations & 17012 & & & 2464 & & & 2464 & & & 2464 & & & 2464 & & \\
\hline Pseudo $\mathrm{R}^{2}$ & 0.155 & & & 0.094 & & & 0.140 & & & 0.159 & & & 0.185 & & \\
\hline Log likelihood & -6508 & & & -2372 & & & -2323 & & & -2301 & & & -2271 & & \\
\hline
\end{tabular}

Note. Significance levels are respectively $1 \%(* * *), 5 \%(* *)$ and $10 \%(*)$. 
Table 5

Marginal effects of motivations

\begin{tabular}{lr}
\hline Factor & Marginal effect \\
\hline Intrumental factor & \\
less than weekly & -0.070 \\
almost weekly & 0.030 \\
almost daily & 0.039 \\
Public good factor & \\
less than weekly & -0.021 \\
almost weekly & 0.009 \\
almost daily & 0.011 \\
Warm glow factor & \\
less than weekly & -0.051 \\
almost weekly & 0.023 \\
almost daily & 0.029 \\
\hline
\end{tabular}

